\title{
Antecedentes de la política agrícola ecuatoriana. Deuda histórica con el pequeño agricultor familiar campesino
}

\section{Antecedents of the Ecuadorian agricultural policy. Historical debt with the small farmer peasant}

Victor, Quinde-Rosales

Rina, Bucaram-Leverone

Martha, Bucaram-Leverone

Carla, Silvera-Tumbaco

Universidad Agraria del Ecuador, Ecuador

Autor para correspondencia: vquinde@uagraria.edu.ec; rbucaram@uagraria.edu.ec; mbucaram@uagraria.edu.ec; csilvera@uagraria.edu.ec

Fecha de recepción: 23 de abril de 2018 - Fecha de aceptación: 20 septiembre de 2018

Resumen: El presente documento sustenta su desarrollo ante la aplicación de políticas agrícolas en el Ecuador, y su intención en priorizar el desarrollo socio-económico del pequeño agricultor campesino, para analizar mencionado problema se buscó determinar la intervención estatal en el desarrollo de políticas bajo los criterios de tenencia de la tierra, gestión del agua, desarrollo tecnológico, financiamiento y desarrollo agrícola, para establecer un enfoque descriptivo de la política agrícola y su búsqueda en saldar una deuda histórica pendiente, se implementó un tipo de investigación descriptivo de diseño no experimental generando el estudio de un problema ya existente, entendiendo a este como la intervención del estado para el desarrollo del pequeño productor agrícola; se evaluó de forma descriptiva la evolución de la política agrícola bajo los criterios antes mencionados. La investigación resultante manifiesta la escasa incidencia que tiene la política agrícola ecuatoriana sobre el productor agrícola familiar campesino a pesar de los intentos generados por pagar la deuda social que tiene el Ecuador sobre el poblador rural.

Palabras claves: política agraria; economía agraria; sociología rural; tenencia de la tierra; gestión del agua; desarrollo tecnológico; financiamiento; desarrollo agrícola

Abstract: This document supports its development in the application of agricultural policies in Ecuador, and its intention to prioritize the socio economic development of the small peasant farmer to analyze mentioned problem was sought to determine the state intervention in the policy development under the criteria of land tenure, water management, technological development, financing and agricultural development. To establish a descriptive approach to agricultural policy and its search to settle a pending historical debt, implemented a kind of descriptive research of non-experimental design generating the study of an existing problem, understanding this as the state's intervention for the development of the small agricultural producer. The evolution of the agricultural policy under the aforementioned criteria was assessed in a descriptive way. The resulting research shows the low incidence of the Ecuadorian agricultural policy on the peasant family farm producer despite attempts to pay the social debt that Ecuador has over the rural population.

Key Words: agrarian policy; agrarian economy; rural sociology; land tenure water management; technological development; financing; agricultural development 


\section{Introducción}

Quinde-Rosales (2015), manifiesta que el sector agrícola no solo es la actividad primaria productiva, el Ecuador debe tomar al sector como un activo estratégico. Yannuzzelli (2017), afirma en este tema que mencionado sector es el eje vinculante de una economía en vía de desarrollo. Echeverri et al. (2002), citado por FAO (2004), expone la capacidad de la agricultura al abordar dimensiones económicas y no económicas que en la actualidad son prioritarias para todos, entendiendo que la agricultura genera un conjunto de externalidades las cuales pueden ocasionar beneficios o perjuicios a la actividad productiva y que se escapan de la misma pero que afectan al conjunto social.

El Ministerio de Agricultura, Ganadería, Acuacultura y Pesca - MAGAP actualmente nombrado como Ministerio de Agricultura y Ganadería - MAG describe que el sector agropecuario provee al menos el $97 \%$ de su consumo alimenticio básico y asegura la alimentación básica de más de 16 millones de ecuatorianos, históricamente ha sido la base de la supervivencia de la población ecuatoriana, siendo el Ecuador autosuficiente en la producción de productos agropecuarios; tan solo se importa el 2,7\% de los alimentos, de éstos el 2,6\% son primarios y el 0,1\% son industrializados (2016). Quinde-Rosales (2011), acota, el estado ecuatoriano debe entender la importancia que tiene el sector agrícola en términos de producción para el consumo interno y su contribución a la economía por medio de las exportaciones sobreponiéndose a otros sectores económicos del país.

El Instituto Nacional de Estadística y Censos - INEC manifiesta en los indicadores laborales generados por la encuesta nacional de empleo, desempleo y subempleo - ENEMDU del primer semestre del 2017 que el 29\% de la población económicamente activa - PEA nacional corresponde a la actividad agricultura, ganadería, caza y silvicultura y pesca; mencionada actividad es una de las principales fuentes de empleo e ingreso para la población rural y principalmente para la agricultura familiar campesina; mencionado indicador en promedio contribuye con el 82\% del PEA rural (2017).

Martínez Valle (2013), describe que el concepto de agricultura familiar se fundamenta en las teorías propuestas por la economía campesina y en la sociología rural, dentro de esta última existen dos escuelas del pensamiento que tratan la temática aquella relacionada con los planteamientos de Chayanov (1985), Shanin (1976), y Tepicht (1973), y los generados por la escuela de sociología rural francesa, donde sobresalen los trabajos de Mendras (1984), y de Jollivet (2003); caracterizando al agricultor familiar o campesino en una dimensión socioeconómica y política.

Es este sector productivo el que alberga a un porcentaje de la población sobre la cual el estado ecuatoriano ha manifestado tener una "deuda histórica social" sobre el poblador rural considerado pequeño productor familiar campesino, este tipo de productor es el que conforma en mayor porcentaje de la población rural ecuatoriana.

Población que ha presentado modificaciones no solo en el Ecuador sino también en toda Latinoamérica y el Caribe durante su desarrollo histórico, Rodríguez (2002), destaca esto al manifestar la diferencia encontrada en 1925 donde el $75 \%$ de la población es rural, mientras que en el 2000 el 24,7\% de la población de Latinoamérica y el Caribe es rural. Villacís et al. (2012), 
ratifica esta aseveración recogiendo la información de los censos de población y vivienda realizados por el INEC, donde manifiesta que en 1950 el 71,5\% de los pobladores pertenecían al sector rural, mientras que en el 2010 el 37,2\% de la población vive en las zonas rurales.

No solo es la reducción porcentual en términos históricos de la población que conforman la zona rural, sino que su tasa de crecimiento intercensal es de $1,47 \%$, porcentaje menor al mostrado por el casco urbano el cual es de 2,24\%. Mencionadas características sobre la pérdida en términos de densidad poblacional de las zonas rurales y el incremento del proceso de urbanización se da principalmente a las desigualdades en variables como conectividad, acceso a servicios básicos, rezago educativo, mayor vulnerabilidad y mayor incidencia de pobreza convirtiendo al sector rural en un ente expulsor promotor del proceso migratorio a pesar de tener una tasa de fecundidad de 1,7 hijos por hogar siendo está más alta que la urbana (Villacís et al., 2012).

Rossel (2012), expone mencionado fenómeno migratorio citando Altimir (1994), y a la Comisión Económica para América Latina y el Caribe - CEPAL (2009 y 2012), bajo la siguiente premisa, era conocido que históricamente la pobreza rural en América Latina es más alta que la urbana, esa idea ha presentado una leve modificación dentro de los últimos años en donde la población pobre dejó de ser en su mayor parte rural debido en gran medida a las migraciones desde el medio rural a las ciudades.

Martínez (2009), menciona que en los espacios rurales existen aún dinámicas importantes que desarrollan los productores a pesar de los factores adversos presentes a nivel económico entendiendo a estos como apertura de mercados, dolarización, elevado costo de mano de obra, desinterés del estado y de los gobiernos locales.

Silva (2005), citado por Martínez (2006), acota expresando que las políticas de desarrollo no toman en cuenta la llamada cultura del territorio la cual engloba la historia, las habilidades, las formas de hacer las cosas con un sello original, la influencia del mismo entorno natural, que influyen en las modalidades de organización económica y social.

Entendiendo esta realidad el Ministerio de Agricultura del Ecuador menciona que los desafíos a enfrentar corresponden a implicaciones nacionales, no solo se relaciona con el sector agropecuario y la población rural sino con la deuda histórica de justicia social de los campesinos, en búsqueda de generar una reproducción intergeneracional de la población ecuatoriana. Es necesario generar políticas explícitas de apoyo a los pequeños productores como elemento crucial para el futuro del sector y de la deuda pendiente desde la perspectiva de equidad social (2016).

La política pública puede relacionarse con el pleonasmo, los griegos entendían a la política como una actividad que debía realizarse en la poli y esta debía ejercerse en público. Para los griegos la política respondía a lo público ya que para ese entonces no existía un concepto de lo individual, la política era pública y lo público era político (Aguilar et al, 2009). Para 1513 esto cambia con la doctrina política de Maquiavelo el cual manifiesta una política heterogénea al del mundo helénico, este propone el hecho que la política se crea en beneficio de algunas élites, careciendo del sentido público que proponían los griegos (Aguilar et al, 2005). 
La política conocida como ciencia desde 1971 gracias a Harold Lasswell bajo el objetivo de estudiar la toma de decisiones en el ámbito de lo público. Lasswell describe que la política pública no es una acción a corto plazo del gobierno en respuesta a una demanda social, las políticas públicas son un conjunto de acciones con un objetivo de interés o beneficio público con lineamientos de acción, agentes, instrumentos, procedimientos y recursos, esta presenta como periodo un largo plazo de uso en relación con los objetivos de las funciones públicas que por naturaleza son permanente (1963).

Quinde-Rosales acota, el concepto de política pública y su definición dentro de la ciencia ha tenido una profunda evolución desde la propuesta de Lasswell, hasta las ideas contemporáneas, la política pública ha formado parte de las ciencias sociales y con un uso inter disciplinario estas forman parte de un complejo de acciones en favor de un interés social. Es bajo esta premisa que se esboza y desarrolla la política agrícola para su aplicación entendiendo las necesidades que requieren los pobladores rurales. En la década de los 80 y 90 se da génesis al concepto e interpretación académica de la política agrícola como fuente de desarrollo socioeconómico de las zonas rurales, esto en colaboración de organizaciones multilaterales como el Banco Mundial y organizaciones no gubernamentales como la Organización para la Cooperación y el Desarrollo Económico (2015).

Instituciones como el Banco Mundial (1986), establecen que el objetivo tradicional a lograr por parte de la política agrícola no es económico, esta presenta prioridades en la protección de la población rural y de sus niveles de ingreso. Esta tendencia confirmada por académicos como Philip Abbott (1998), donde prevalece la redistribución del ingreso al sector agropecuario, promoviendo los precios, ingresos y ganancias a sus subsectores, es el objetivo a seguir por parte de los países de Latinoamérica.

La premisa que impera en países en vías de desarrollo es utilizar la política sectorial para alterar la situación de los pequeños y medianos productores en beneficio del sector agropecuario y el logro de la soberanía alimentaria. Para el Ecuador esto es prioritario en especial para los pequeños campesinos. La aplicación de la política agrícola en cualquiera de sus ejes de intervención presenta una relación con la seguridad alimentaria principalmente en establecer la capacidad de las familias pobres para obtener acceso a los alimentos en las cantidades necesarias entendiendo que los precios y la disponibilidad de los alimentos tienden a ser más volátiles que en los países industrializados (FAO, 2004).

Para la realización del presente estudio se pretende analizar los antecedentes de la política agrícola ecuatoriana y como estos no han podido saldar una deuda social histórica. Para ello se evaluará las políticas agrícolas ecuatorianas desde 1950 con el primer censo de población y vivienda realizado en territorio ecuatoriano para establecer la relación que presenta la aplicación de las políticas y su accionar en beneficio del poblador rural. Bajo la tendencia sociológica podemos establecer la relevancia del sector agropecuario en el desarrollo de la política nacional y como esta se ha convertido en una herramienta que busca la reducción de la pobreza rural convirtiéndose en puntal que garantice el saldo de la deuda social que tiene el poblador rural y del crecimiento económico nacional, contribuyendo en el desarrollo de condiciones de 
producción dentro del desarrollo territorial rural y de dignificación del nivel de vida de los campesinos ecuatorianos.

\section{Métodos}

La presente investigación se enmarcó en un tipo de razonamiento inductivo mediante la cual, obtuvo conclusiones generales a partir de premisas que contienen datos particulares o individuales obtenidos por la aplicación de los diferentes tipos de políticas agrícolas usadas en Ecuador. La investigación centra su interés en establecer las implicaciones que generan las políticas de tenencia de tierras, gestión del agua, desarrollo tecnológico, financiamiento y las que promueven estrategias de desarrollo social. Se esboza como proceso de desarrollo de la investigación un proceso unimétodo utilizando como paradigmas el pragmático según Lewin (1946), citado por Duque (2015), permite reflejar los procesos investigativos esclarecen el quehacer profesional en el manejo de problemas sociales específicos; Duque (2015), acota interpretando al paradigma como una investigación o acción que estudia una situación social para buscar una mejora en el accionar de la misma.

Para el logro de mencionado objetivo se analizó el comportamiento histórico de la política agrícola para explicar si su aplicación contribuyó a reivindicar a la población social. La información recolectada y analizada dentro del proceso investigativo es de carácter bibliográfica de fuente secundaria. Para el desarrollo del artículo se buscó determinar la relación existente entre la aplicación de la política agrícola y su externalidad en beneficio de la población rural como una contribución sociológica para establecer la importancia de este en el estado ecuatoriano, para ello se evaluó el resultado generado por la política agrícola años atrás, describiendo los resultados, esto como aporte académico al desarrollo histórico del desempeño estatal en el Ecuador.

El diseño de investigación del documento estableció un periodo de estudio de 67 años de las variables que componen la tipología de las políticas agrícolas entendiendo a estas como las políticas que generan recursos para el desarrollo productivo del sector y las que generan un desarrollo socioeconómico.

\section{Resultados y Discusión}

El análisis de los antecedentes de la política agrícola se centró en la aplicación de este instrumento y como estos deben promover el uso adecuado de los recursos y fomentar la productividad agropecuaria y el desarrollo social y económico de la población rural.

Para evaluar el aporte que ha generado la política agropecuaria ecuatoriana sobre el pequeño agricultor campesino, es pertinente analizar el comportamiento de la política en aspectos de tenencia de tierra, gestión del agua, financiamiento, desarrollo tecnológico y agrícola; para con ello determinar la contribución que ha generado el estado en favor de la productividad agropecuaria en especial si el alcance de la política pública va dirigido al pequeño productor campesino (Tabla $\mathrm{N}^{\circ} 1$ ).

Tabla 1. Caracterización de las Políticas Agrícolas 
- Gestión del Agua

- Desarrollo Tecnológico

- Financiamiento

- Desarrollo Agrícola

Fuentes: Organización de las Naciones Unidas para la Alimentación y la Agricultura - FAO. Caracterización basada en lo expuesto por el libro Política de desarrollo agrícola. 2004

Para contribuir con el desarrollo productivo del pequeño productor agropecuario, se puede argumentar que la política agrícola ecuatoriana busca contribuir en la generación de recursos para el desarrollo productivo de la actividad antes mencionada. A su vez agregar que el objetivo de la política pública ecuatoriana vincula a la pequeña agricultura campesina familiar como parte del proceso productivo, aunque en toda su vida republicana no ha logrado tal premisa.

La tenencia de la tierra ha sido parte de la génesis de la política agrícola del Ecuador junto con la primera reforma agraria a finales de los años 60 hasta la actualidad. A pesar del incremento de números de predios y la extensión de la frontera agrícola, el gobierno ecuatoriano no ha podido corregir la inequidad en la tenencia de tierras agropecuarias en la actualidad existe una marcada fragmentación que diferencia drásticamente a quienes tienen menos de 20 hectáreas de los que poseen más de ella $\left(\right.$ Tabla $\left.\mathrm{N}^{\circ} 2\right)$.

Tabla 2. Evolución de la Tenencia de la Tierra 1954 - 2013. Ecuador

\begin{tabular}{|c|c|c|c|c|c|c|c|c|}
\hline \multirow[t]{2}{*}{ Estrato } & \multicolumn{2}{|c|}{1954} & \multicolumn{2}{|c|}{1974} & \multicolumn{2}{|c|}{2001} & \multicolumn{2}{|c|}{2013} \\
\hline & UPA & Superficie & UPA & Superficie & UPA & Superficie & UPA & Superficie \\
\hline$<1$ ha. & 92387 & 46000 & 145550 & 63263 & 248398 & 95834 & 202694 & 80065 \\
\hline 1 - 5 ha. & 159299 & 386200 & 201297 & 475405 & 286911 & 678391 & 292073 & 683846 \\
\hline 5 - 10 ha. & 36250 & 271500 & 54935 & 377756 & 101066 & 688987 & 112257 & 756621 \\
\hline 10 - 20 ha. & 21400 & 294300 & 41425 & 557535 & 75660 & 1017807 & 91384 & 1218697 \\
\hline 20 - 50 ha. & 19415 & 591500 & 42537 & 311974 & 76792 & 2372027 & 91755 & 2802085 \\
\hline 50 - 100 ha. & 8327 & 547200 & 22276 & 1352697 & 34498 & 2242409 & 35848 & 2273060 \\
\hline$>100$ ha. & 7156 & 4263000 & 11091 & 3810773 & 13557 & 5260375 & 15034 & 3943983 \\
\hline Total & 344234 & 6399700 & 519111 & 6949403 & 836882 & 12355830 & 841045 & 11758357 \\
\hline Índice de Gini & &, 87 & & 82 & & 81 & & 76 \\
\hline
\end{tabular}

Fuentes: INEC. Censo Nacional Agropecuario años: 1954, 1974, 2001; Encuesta de Superficie y Producción Agropecuaria ESPAC INEC 2013

Es necesario mencionar que la desigual distribución de tierras genera externalidades en la tecnificación e investigación de la práctica agropecuaria, así como problemas en el acceso de tierras en términos de equidad de género, como para los jóvenes, grupos de la población que demandan atención.

El Ecuador no ha presentado una política agrícola que infiera en beneficio de la tenencia de la tierra, ninguna de las cuatro reformas agrarias que se esbozaron en el Ecuador y que guardaron la premisa de una igualdad en la distribución de la tierra agrícola tuvo un claro impacto en este sentido. La irregularidad en la participación porcentual de la tenencia de la tierra a través del tiempo solo se explica con el constante incremento de la frontera agrícola (Tabla $\mathrm{N}^{\circ}$ 3).

Tabla N 3. Tasa de Participación de la Tenencia de la Tierra 1954 - 2013. Ecuador 


\begin{tabular}{crrrrrrrr}
\hline Estrato & \multicolumn{2}{c}{$\mathbf{1 9 5 4}$} & \multicolumn{2}{c}{$\mathbf{1 9 7 4}$} & \multicolumn{2}{c}{$\mathbf{2 0 0 1}$} & \multicolumn{2}{c}{$\mathbf{2 0 1 3}$} \\
& UPA & Superficie & UPA & Superficie & UPA & Superficie & UPA & Superficie \\
\hline < 1 ha. & $27 \%$ & $1 \%$ & $28 \%$ & $1 \%$ & $30 \%$ & $1 \%$ & $24 \%$ & $1 \%$ \\
$\mathbf{1 ~ - ~ 5 ~ h a . ~}$ & $46 \%$ & $6 \%$ & $39 \%$ & $7 \%$ & $34 \%$ & $5 \%$ & $35 \%$ & $6 \%$ \\
$\mathbf{5}$ - 10 ha. & $11 \%$ & $4 \%$ & $11 \%$ & $5 \%$ & $12 \%$ & $6 \%$ & $13 \%$ & $6 \%$ \\
$\mathbf{1 0}$ - 20 ha. & $6 \%$ & $5 \%$ & $8 \%$ & $8 \%$ & $9 \%$ & $8 \%$ & $11 \%$ & $10 \%$ \\
$\mathbf{2 0}$ - 50 ha. & $6 \%$ & $9 \%$ & $8 \%$ & $4 \%$ & $9 \%$ & $19 \%$ & $11 \%$ & $24 \%$ \\
$\mathbf{5 0}$ - 100 ha. & $2 \%$ & $9 \%$ & $4 \%$ & $19 \%$ & $4 \%$ & $18 \%$ & $4 \%$ & $19 \%$ \\
$>$ 100 ha. & $2 \%$ & $67 \%$ & $2 \%$ & $55 \%$ & $2 \%$ & $43 \%$ & $2 \%$ & $34 \%$ \\
Total & $100 \%$ & $100 \%$ & $100 \%$ & $100 \%$ & $100 \%$ & $100 \%$ & $100 \%$ & $100 \%$ \\
\hline
\end{tabular}

Fuentes: INEC. Censo Nacional Agropecuario años: 1954, 1974, 2001; Encuesta de Superficie y Producción Agropecuaria ESPAC INEC 2013

La importancia de generar una equidad en términos de distribución de la tierra radica en que el 72\% de las Unidades Productoras Agrícolas (UPA) concentran solo el 13\% de las tierras productivas agrícolas, en un país donde uno de sus mayores rubros económicos es la agricultura y que guarda como premisa la valoración de la agricultura familiar campesina, agricultura que actualmente se denomina de subsistencia y que en el proceso histórico el aporte que tiene este hacia el crecimiento económico es cada vez menor (Tabla $\mathrm{N}^{\circ} 4$ ).

Tabla N 4. Valor Agregado de la agricultura según su tipo. Ecuador 2007-2013*

\begin{tabular}{|c|c|c|c|c|c|c|c|}
\hline Años & $\begin{array}{c}\text { Valor } \\
\text { Agregado Total } \\
\text { Agricultura }\end{array}$ & $\begin{array}{c}\text { Valor Agregado } \\
\text { Agricultura } \\
\text { Familiar }\end{array}$ & $\%$ & $\begin{array}{c}\text { Valor Agregado } \\
\text { Agricultura Semi } \\
\text { Comercial }\end{array}$ & $\%$ & $\begin{array}{c}\text { Valor Agregado } \\
\text { Agricultura } \\
\text { Comercial }\end{array}$ & $\%$ \\
\hline 2007 & 7.418 .218 & 743.969 & $10 \%$ & 1.336 .597 & $18 \%$ & 5.337 .651 & $72 \%$ \\
\hline 2008 & 8.650 .992 & 981.102 & $11 \%$ & 1.656 .156 & $19 \%$ & 6.013 .734 & $70 \%$ \\
\hline 2009 & 9.605 .643 & 885.966 & $9 \%$ & 1.664 .290 & $17 \%$ & 7.055 .387 & $73 \%$ \\
\hline 2010 & 10.544 .840 & 1.113 .041 & $11 \%$ & 1.947 .596 & $18 \%$ & 7.484 .204 & $71 \%$ \\
\hline 2011 & 11.807 .184 & 1.118 .897 & $9 \%$ & 2.071 .381 & $18 \%$ & 8.616 .906 & $73 \%$ \\
\hline 2012 & 11.707 .902 & 925.191 & $8 \%$ & 1.895 .739 & $16 \%$ & 8.886 .973 & $76 \%$ \\
\hline 2013 & 13.083 .635 & 918.967 & $7 \%$ & 2.022 .524 & $15 \%$ & 10.142 .144 & $78 \%$ \\
\hline
\end{tabular}

Fuente: Ministerio de Agricultura 2016 con información del Banco Central del Ecuador. Boletín Anuario $\mathrm{N}^{\circ} 36$ agosto 2014; ESPAC INEC 2013

*El Valor Agregado Bruto de la Agricultura considero la contabilización de la producción que no tiene destino comercial (autoconsumo, semillas, alimentos para animales y otros usos no comerciales), que no son captados en la cuantificación convencional, y agregar dichos valores, al valor de la producción registrado en el Sistema de Cuentas Nacionales (que es el valor de la producción que según Estadística de Superficie de Producción Agrícola Continua -

ESPAC se destina a la venta). Dicha corrección se practicó utilizando los datos del ESPAC 2013; "venta",

"Autoconsumo", y "Otros usos" (semillas, alimentos para animales y otros usos no comerciales)

El INEC por medio de la Encuesta de Superficie y Producción Agrícola Continua ESPAC (2013), informa que el pequeño agricultor campesino se concentra en UPAs de menor número de hectáreas (Tabla $\mathrm{N}^{\circ} 5$ ).

Esto a pesar de que el Ministerio de Agricultura y Ganadería - MAG define al pequeño agricultor campesino bajo los criterios de valor anual de la producción total de la Unidad de Producción Agrícola - UPA menor a 10.000 dólares, al menos el 50\% de la mano de obra empleada en la UPA sea no remunerada, y que la persona productora principal reside en la UPA. 
Tabla N5. Caracterización de la agricultura por tamaño (UPAS), según tipo de agricultura. Ecuador 2013

\begin{tabular}{ccccccccc}
\hline Tamaño & \multicolumn{9}{c}{ Agricultura } \\
& Pequeña & \multicolumn{2}{c}{ Mediana } & \multicolumn{2}{c}{ Empresarial } & \multicolumn{2}{c}{ Total } \\
& Upa & \% & Upa & \% & Upa & \% & Upa & \% \\
\hline Menos 1 Ha & 117.119 & 27,5 & 55.085 & 17,8 & 80 & 0,2 & 172.285 & 22,3 \\
1 A 2 Ha & 70.311 & 16,5 & 33.502 & 10,8 & 225 & 0,6 & 104.039 & 13,5 \\
2 A 3 Ha & 51.215 & 12,0 & 24.524 & 7,9 & 152 & 0,4 & 75.891 & 9,8 \\
3 A 5 Ha & 54.724 & 12,9 & 38.739 & 12,5 & 154 & 0,4 & 93.617 & 12,1 \\
5 A 10 Ha & 48.880 & 11,5 & 54.403 & 17,6 & 2.593 & 7,0 & 105.876 & 13,7 \\
10 A 20 Ha & 35.184 & 8,3 & 40.003 & 12,9 & 9.927 & 26,8 & 85.115 & 11,0 \\
20 A 50 Ha & 33.523 & 7,9 & 40.145 & 13,0 & 12.915 & 34,8 & 86.583 & 11,2 \\
50 A 100 Ha & 11.723 & 2,8 & 16.146 & 5,2 & 6.611 & 17,8 & 34.480 & 4,5 \\
100 A 200 Ha & 2.399 & 0,6 & 4.710 & 1,5 & 2.367 & 6,4 & 9.476 & 1,2 \\
200 A Más Ha & 516 & 0,1 & 2.214 & 0,7 & 2.045 & 5,5 & 4.775 & 0,6 \\
Total & $\mathbf{4 2 5 . 5 9 6}$ & $\mathbf{1 0 0}$ & $\mathbf{3 0 9 . 4 7 1}$ & $\mathbf{1 0 0}$ & $\mathbf{3 7 . 0 6 9}$ & $\mathbf{1 0 0}$ & $\mathbf{7 7 2 . 1 3 6}$ & $\mathbf{1 0 0}$ \\
\hline
\end{tabular}

Fuentes: Ministerio de Agricultura 2016 con información de la Encuesta de Superficie y Producción Agropecuaria ESPAC INEC 2013

La tierra es un factor indiscutible para el desarrollo productivo de la agricultura pues es este recurso la herramienta principal del proceso productivo, del mismo modo se convierte bien distribuido en un factor de crecimiento económico para los pequeños productores quienes deben tener especial atención ya que estos representan el mayor porcentaje de la población rural. Es menester de la República del Ecuador generar un diseño de política pública eficiente para la redistribución de tierras que beneficie a la agricultura familiar campesina y a la productividad agrícola del país.

Esta aseveración se valida bajo lo expuesto por Munro et al., quien manifiesta "En muchos casos las respuestas a las preocupaciones sobre la sostenibilidad ambiental, los conflictos sociales y la seguridad alimentaria de la población vulnerable han sido afectadas por la tenencia de la tierra y tienen un impacto sobre la misma. Dejar de considerar los efectos de la tenencia de la tierra al inicio de un proyecto probablemente determinará resultados no anticipados. Esta omisión puede conducir a que el proyecto no genere mejoría alguna. En ciertos casos, puede hasta empeorar la situación, por ejemplo, desposeyendo inadvertidamente a la gente de sus derechos sobre la tierra..."(2002).

Para brindar el acceso, disponibilidad, uso y estabilidad del suministro alimenticio en el Ecuador no basta con brindar una equidad en la tenencia del recurso más importante para la producción agrícola, la tierra, con el objetivo de generar una producción diversificada la cual aporta las familias campesinas rurales dejando de lado la producción monopólica y rentista de los productores empresariales. El pequeño productor campesino requiere de otros recursos que incentive el desarrollo productivo de sus tierras.

Uno de esos recursos es el agua, las políticas públicas que promueven la gestión de riego tienen como objetivo la equidad en la distribución del recurso, la eficiencia en el uso del regadío para la producción agrícola y la sustentabilidad del riego en términos ambientales e institucionales. La CEPAL (1954), describe al Ecuador en términos de riego que para el año de 
su análisis este disponía de una escasa superficie con riego, con obras realizadas por iniciativa de particulares.

El Ecuador en 1936 legisla para establecer que toda el agua que corre por cauces naturales forma parte del estado, con el fin de reglamentar su uso. Para 1944, se promueve la Ley de Riego y Saneamiento, entendiendo que las obras de riego tienen un interés nacional, siendo esta preocupación del estado. El ministerio de obras públicas asume las funciones del uso del agua para aspectos productivos y para ello se crea la caja nacional de riego (CEPAL, 1954).

Este brazo ejecutor del riego en el Ecuador sostuvo continuamente problemas en el financiamiento de sus proyectos, adicionalmente la obra realizada para la propagación del riego era considerada durante décadas una obra civil, dejando de lado la lógica integral que brinda el interés por el riego campesino, el cual integra componentes como los aspectos técnicos, socioorganizativos y culturales, políticos, legales y ambientales (CEPAL, 1954).

En 1966 se crea por ley el Instituto Ecuatoriano de Recursos Hidráulicos - INERHI con la finalidad de propender al mejor aprovechamiento y protección de los recursos hídricos del país. En 1992 se da inicio a un periodo de reformas legales y administrativas que apuntaban a modernizar la gestión pública, generando que en 1994 desaparezca mencionado instituto y se crea a cambio el Consejo Nacional de Recursos Hídricos - CNRH limitado a la planificación, organización y concesión de aprovechamiento del agua (Bucaram, 2017).

Bucaram (2017), expone que, a pesar de las reformas legales y el proceso de modernización del Estado, la situación no varía, sino que presentó mayores inconvenientes ante la existencia de varias agencias involucradas con el recurso hídrico y menor recursos financieros y económicos para desarrollar la buena gestión de las mismas. Se puede argumentar que la gestión de riego no presentó un interés en articularse con la dinámica social, productiva y ambiental; que genera el sector agrícola y rural. Es bajo esta premisa que el Ministerio de Agricultura (2016), manifiesta que el acceso hídrico no ha cambiado durante el proceso histórico del Ecuador, los pequeños agricultores campesinos carecen del recurso hídrico, mientras que los grandes productores la concentran; creciendo constantemente la presión por el acceso y uso del agua.

A pesar de esto la Subsecretaria de Riego y Drenaje (2011), dentro del Plan Nacional de Riego y Drenaje - PNRD manifiesta que el Ecuador posee una gran riqueza hídrica, su promedio per cápita de agua en el 2000 alcanzó $34.161 \mathrm{~m} 3$ al año mientras que en el 2005 obtuvo 32.270 m3 al año. Galárraga (2000), manifiesta que la disponibilidad de agua tomando en cuenta todos los sistemas hidrográficos, es de $432.000 \mathrm{hm} 3$ al año; de esto solo $115.00 \mathrm{hm} 3$ al año pertenecen de la vertiente del Pacífico, mientras que 317.000 hm3 al año nacen de la Amazonía; de esto solo el $34 \%$ se considera como disponibilidad efectiva.

En la actualidad el estado ecuatoriano promueve dentro de la política agrícola el acceso, distribución y gestión del riego parcelario en zonas aptas para la producción agrícola, entendiendo que el agua es uno recurso importante para el ser humano, pues de ella depende la agricultura y la alimentación (MAGAP, 2016). Gaybor (2008), manifiesta que la política agraria a pesar de haber cambiado en los últimos años, esta no ha influido sobre el acceso del recurso hídrico (y tierra); antes bien los distintos modelos de desarrollo rural que se implementaron 
estuvieron se fundamentan en la concentración de la tierra, del agua y demás recursos productivos.

A nivel institucional el estado considero desde 1972 con la primera Ley de Aguas un bien nacional del uso público, posteriormente en 2014 la nueva normativa interpreta a los recursos hídricos como estratégicos para la nación y el estado, bajo esta premisa se debe garantizar a toda la población el acceso y aprovechamiento equitativo del agua.

El Ecuador cuenta con 76 sistemas de riego público los cuales generan una cobertura de 162.363 hectáreas regadas las mismas que benefician a más de 336.000 familias rurales productoras agrícolas. A nivel general la superficie bajo infraestructura de riego es de 942.000 hectáreas regadas, de estas el $25 \%$ pertenece a pequeños y medianos productores agropecuarios con menos de 20 hectáreas. En este término de determinar el estado de la infraestructura de riego nacional encontramos que el $9 \%$ de la estructura está en estado "muy bueno", interpretándolo como de funcionamiento al 100 y $75 \%$ de su capacidad. El 53\% es de estado "bueno", funcionando al 75 y $50 \%$ de su capacidad. El 22\%, en estado "regular", con un 50 y $25 \%$ de su capacidad; y el 6\% en estado "malo", con un 25\% de su capacidad (MAGAP, 2016). Es necesario mencionar que los canales terciarios y principales son los que en gran porcentaje ocupan un estado regular.

Acosta (2010), expone a la falta de planificación con un enfoque integral como causa principal de la ineficiencia de los sistemas de riego, generando principalmente problemas de infraestructura, argumentando que la deficiencia en la gestión afecta la eficiencia de un sistema de riego.

El Ministerio de Agricultura aclara esta teoría argumentando en el PNRD (2013) que los diversos sistemas de riego promueven deficiencias, teniendo como promedio un $37 \%$ de uso ineficiente del caudal en los sistemas de riego, de forma específica los sistemas comunitarios aprovechan el $50 \%$ del caudal, el $61 \%$ en los públicos y el $78 \%$ en los privados.

A nivel parcelario el aprovechamiento del recurso hídrico a través de su riego presenta un promedio nacional del 61,26\%, a nivel regional el Litoral el promedio de aprovechamiento del recurso agua con fines de riego llega al $61,96 \%$, mientras que en la Sierra se presenta una media de aprovechamiento del agua de riego a nivel parcelario del 60,55\%, gracias a sus características agroecológicas (MAGAP, 2016).

Al mismo tiempo se expone los problemas históricos que la región Costa y Amazonia han soportado en tema de drenaje en suelo de producción agrícola, el Ministerio de Agricultura manifiesta que mencionadas regiones por su topografía son vulnerables al anegamiento de sus áreas productivas, debido al exceso o intensidad de las precipitaciones y su consecuencia el desborde de los recursos hídricos en época invernal (PNRD, 2013).

El efecto causado por el fenómeno del Niño en la Costa refleja los problemas más notorios en términos de drenaje, son las provincias de Manabí, Los Ríos, Guayas, El Oro y Esmeraldas las más afectadas. En casos más severos se presentan dos fenómenos climáticos externos como las inundaciones y las sequias, la provincia de Manabí es una zona altamente 
vulnerable ante estos fenómenos, el invierno causa incalculables pérdidas económicas y dificulta la programación de un manejo adecuado del recurso hídrico debido a sus inundaciones (MAGAP, 2016). Bucaram (2017), agrega que el país es vulnerable al fenómeno de erosión gracias a sus características topográficas y climáticas, estimando un $48 \%$ de territorio erosionado, sus principales causas son el sobre pastoreo, la deforestación, el mal manejo del suelo y el agua.

La necesidad de implementar adecuados sistemas de riego y drenaje en el país ubica a los entes públicos a tomar como eje importante al pequeño productor agrícola entendiendo la trascendencia que tiene mejorar los procesos de gestión que afiancen a organizaciones comunitarias y de regantes en la planificación, seguimiento, evaluación y control de gestión pública del riego parcelario. El Estado debe asumir la gestión del agua dentro de su plan de desarrollo, ya que el buen uso y su distribución equitativa bajo aspectos de sustentabilidad son importantes para el desarrollo productivo del país de la sociedad en términos de uso.

El Banco Mundial - BM (1994), manifiesta la necesidad de definir políticas hídricas nacionales claras con planes de manejo de los recursos hídricos, apoyados en planes regionales y de cuencas. Las estrategias para el uso del agua deben ser evaluadas sistemáticamente, teniendo en cuenta el equilibrio entre los criterios y las medidas de gestión de la oferta y de la demanda del recurso.

El desarrollo tecnológico persigue como objetivo el ser productivos debiendo generar, adaptar y validar tecnologías, además de desarrollar procesos innovadores que permitan aumentar los rendimientos y la eficiencia en el uso sostenible de los recursos naturales. La política agrícola ecuatoriana en el desarrollo de su visión como perspectiva del futuro agrícola del país a ha priorizado la creación de distintas instituciones especializadas para abordar los temas de generación de tecnología, capacitación, fortalecimiento gremial, sanidad agropecuaria, sistemas de información y comercialización. A pesar de ello mencionadas instituciones carecen de instrumentos que vinculen sus procesos y conocimientos con los pequeños productores.

Jaramillo describe de forma histórica el proceso evolutivo que ha presentado el país para articular el desarrollo tecnológico en la política agrícola, argumenta tres etapas, intentos por construir un sistema de investigación y transferencia de tecnología de 1987 a 1996; hacia la privatización de los servicios de transferencia de tecnología de 1996 al 2005; y recuperación del papel del Estado y la orientación de los servicios de transferencia de tecnología en el marco del Buen Vivir del 2007 a la actualidad (2013). Esta política de desarrollo es de tal importancia para el Ecuador que, en la actual Constitución, la Asamblea constituyente (2008), menciona en su artículo 276 "Fortalecer la diversificación y la introducción de tecnologías ecológicas y orgánicas en la producción agropecuaria"; mientras que en el artículo 334 se divulga "Impulsar y apoyar el desarrollo y la difusión de conocimientos y tecnologías orientados a los procesos de producción”.

El Ministerio de Agricultura del Ecuador establece que a la actualidad persisten ciertos rasgos que mantienen al Ecuador insuficiente investigación, desarrollo tecnológico e innovación. Estos rasgos los describe como dificultades en el enfoque y empleo de métodos que se sigue en el extensionismo y la práctica de investigación agropecuaria; escasa innovación tecnológica y 
social para el desarrollo productivo de los pequeños productores; desaparición de las buenas prácticas agrícolas; perdida del conocimiento ancestral; importación de tecnologías extranjeras orientadas a los grandes productores con una variabilidad de los precios (MAGAP, 2016).

Se puede argumentar que el extensionismo como tal y la transferencia de tecnología presenta la siguiente problemática, asumir que los agricultores son resistentes al cambio sin establecer con anterioridad la pertinencia de la innovación; la innovación tecnológica generada por el aparato público o por organismos no gubernamentales emplean un proceso lineal para su transferencia sin entender lo importante que es un proceso horizontal y crítico del sistema; se asume condiciones homogéneas de los productores en términos sociales, productivos y de mercado cuando en el Ecuador esos comportamientos son heterogéneos.

La demanda insatisfecha de extensionismo y transferencia de tecnología asciende a 425.596 productores que conforman la agricultura campesina y a 309.471 medianos productores (MAGAP, 2016). Este proceso presenta cuatro modelos. Productor de pequeña escala, con agricultura de autoabastecimiento con poca articulación al mercado; Productor de mediana y gran escala, con producción directamente relacionada con el mercado nacional; Productor de mediana escala, con producción destinada a la exportación. Acciones desarrolladas por gremios de productores; Ganadero lechero de pequeña escala, articulado a empresas de procesamiento para el mercado nacional (Jaramillo, 2013).

La inversión en investigación agrícola se convierte en el instrumento que le proporciona el rol principal al Estado en pro del desarrollo productivo del sector agrícola. El gasto total en investigación y desarrollo es una de las principales manifestaciones del interés que persigue el estado para el desarrollo de innovación y tecnología para el territorio patrio y en especial el del sector agrícola, según la Red de Indicadores de Ciencia y Tecnología -Iberoamericana e Interamericana - RICYT, en el 2014 el gasto generado en investigación en proporción del Producto Interno Bruto - PIB fue del 1\%, por debajo de países como Argentina, México y Brasil. El promedio de asignación de recursos en ciencia y tecnología, investigación y desarrollo experimental para América Latina es, en general, reducido y se encuentra cercano al 2\% del PIB en el 2014 (RICYT, 2016).

Parte del logro para el desarrollo de la productividad agrícola recae en la agricultura campesina familiar la cual representa el mayor porcentaje de la población en el sector rural, correlacionalmente son los que perciben menores ingresos por la producción agrícola, la adopción de tecnología innovación y extensionismo se convierte en un instrumento de contrapeso ante el declive de la productividad promedio de los países latinoamericanos.

Esta premisa guarda relación con lo expuesto por Dina Umali Deininger "El crecimiento acelerado de la población ha desencadenado un vertiginoso aumento en la demanda de alimentos, mientras que la capacidad de muchas naciones para producirlos se restringe cada vez más, debido a la disminución de las posibilidades de incorporar nuevas tierras al cultivo y a la caída de la productividad en zonas sobreexplotadas, como consecuencia de la degradación de los recursos naturales. ... Al mismo tiempo, una significativa mayoría de los pobres continúa dependiendo de la agricultura. De los 720 millones de pobres identificados por el Banco Mundial... 75 por ciento vive en zonas rurales. Por lo tanto, un importante componente de las 
estrategias de desarrollo agrícola y reducción de la pobreza es aumentar los ingresos de los agricultores a través de mejoras en la productividad" (1997).

El financiamiento o el crédito se establecen como otro de los recursos que contribuye al desarrollo de la productividad agropecuaria, desde la década de los 60 el interés del estado por el financiamiento es fomentar y proteger la inversión de capitales mediante sistemas adecuados de crédito supervisado y orientado. Esta premisa persigue a las políticas públicas del Ecuador, a partir de esta década hasta la actualidad el fomento de créditos iba ligado con la orientación productiva que promovía el estado a través de sus institutos inicialmente la avicultura y su desarrollo de mecanización y posteriormente con el uso de químicos promovidos por el desarrollo de la productividad agrícola y la aplicación de la reforma agraria.

A partir del 2004 el estado ecuatoriano promueve los servicios financieros públicos y la democratización del crédito, esto ante la existencia de condiciones desfavorables de los sectores productivos para acceso a crédito y al reducido desarrollo de los mercados de factores, productos e insumos para la producción agropecuaria (crédito, insumos, asistencia técnica, etc.). Esta realidad el Ministerio de Agricultura lo sintetiza mencionando que "...la falta de acceso a crédito productivo y de movilización de la cosecha. Los pequeños productores recurren al microcrédito a través de fomentadores o de comercializadores, pues no son sujetos de crédito bajo los parámetros financieros convencionales, o los productos crediticios no se ajustan a esos requerimientos financieros y la entrega oportuna de recursos. Esto conduce a entregar sus cosechas al precio que determine el fomentador o comercializador" (2016).

El crédito o la disposición de crédito agropecuario en el Ecuador es tan complejo que para su evaluación no solo se debe tomar en cuenta la emisión del crédito, sino también las limitantes para generarlo, la ausencia de titulación de la tierra se convierte en una limitante ante su incapacidad de ser garantía. Se puede también argumentar que la banca privada ve poco atraíble la generación de crédito ante la dispersión de los productores.

Quinde-Rosales da pautas del comportamiento del crédito público y privado en beneficio del sector agrícola en el periodo 2005 - 2015, este menciona que "el promedio de participación del sector agrícola dentro de las asignaciones crediticias del sistema bancario nacional... alcanza un 7\%,... los Bancos Privados Nacionales tienen el 4\% y las Instituciones Financieras Publicas el 10\% de la participación respectiva de sus subsectores" (2017).

Dentro de mencionado periodo se ha presentado un crecimiento del $66 \%$ en términos de montos asignados a créditos. Este crédito fue asignado entre las provincias de Pichincha 35\%, Guayas 27\%, Los Ríos 8\%, El Oro 5\%, Tungurahua 4\%, Azuay 4\%, Santo Domingo de los Tsáchilas 4\%, Manabí con un 3\% y las provincias restantes apenas suman el 10\% (QuindeRosales, 2017).

El mercado de factores como el crédito es uno de los más complejos para ser vinculado con un sector socio-productivo como es el caso de la agricultura y en especial del pequeño agricultor campesino. El estado entiende esta realidad y asume el rol con instituciones públicas que ofrecen el crédito, pero a pesar de los esfuerzos vistos en los últimos años el sistema financiero aun no es un recurso que genere un punto de quiebre a favor de la productividad del sector agropecuario ya sea por la mala asignación de créditos, por el re direccionamiento del 
crédito a los grandes productores, o el poco interés que presente la banca privada por desarrollar este tipo de créditos productivos.

Este planteamiento encuentra su validez ante el análisis pesimista que presentan Klein, Meyer, Hannig, Burnett, y Fiebig al mencionar que "las reformas de mercado y las privatizaciones en curso no han producido todavía apreciables mejoras en la provisión de servicios de apoyo a la agricultura. Tampoco han aumentado la rentabilidad agrícola. Más bien, con frecuencia, los pequeños agricultores tienen menos acceso que antes a los servicios bancarios rurales y a los préstamos agrícolas institucionales. Una razón importante es la ausencia de un adecuado marco de políticas de financiación agrícola y rural” (1999).

La predisposición de la política pública en generar estrategias que fomenten el desarrollo rural en beneficio de revalorizar de forma histórica, social y económica al pequeño productor familiar campesino, es prioritario no solo para los intereses productivos del sector agrícola, ni para los del estado en saldar su deuda social con este sector, sino que puede permitir un acceso a los alimentos de forma equitativa. Para establecer la importancia de la agricultura y la población que la conforma es necesario entender las externalidades que genera el desarrollo agroproductivo del país, principalmente sobre la población rural del Ecuador. El sector agrícola es uno de los sectores de principal importancia para el estado en términos de desarrollo socioeconómico, esto ante el nivel de población que interviene en este sector y el nivel de ingresos que presenta. Dentro del periodo de análisis 2007 - 2013 la Población Económicamente Activa PEA describe que en promedio el sector agrícola contribuye con el 68\% del PEA rural, mientras que en términos globales este aporta con el 32,6\% (Tabla $\mathrm{N}^{\circ} 6$ ).

La agricultura es el principal sector en términos de contribución al PEA nacional después del comercio con el $18 \%$ y la industria manufacturera con el $10 \%$, recogiendo a la mayor cantidad de personas que carecen de un conocimiento académico para generar otra actividad laboral. El interés del estado por generar inversión en el desarrollo del sector agropecuario radica en la importancia que tiene mencionado sector en el desarrollo social de los grupos poblacionales más desfavorable. La aplicación de políticas para generar una estructura del sector agropecuario que mantenga a la población en las zonas rurales evitando la migración hacia las zonas urbanas generando procesos de incremento en el casco urbano sin generar un proceso de planificación.

El sector agrícola alberga a una cantidad considerable de personas del género femenino, las cuales presentan mayores desventajas ante el proceso productivo y de generación de ingresos en función del escaso acceso a los recursos productivos, el género femenino encuentra su importancia dentro de la participación en la tenencia de la tierra la cual es mayoritaria en la mujer en UPAs de menos de una hectárea, hasta 50 hectáreas; tanto del pequeño agricultor campesino como de los productores empresariales y medianos (Tabla $\mathrm{N}^{\circ} 7$ ). 
Tabla N 6. Estructura de la Población Económicamente Activa por rama de actividad. Ecuador

\begin{tabular}{|c|c|c|c|c|c|c|c|c|c|c|c|c|c|c|c|c|c|}
\hline $\begin{array}{l}\text { A } \\
\text { Agricu } \\
\text { ltura, } \\
\text { ganad } \\
\text { ería, } \\
\text { silvicu } \\
\text { litura y } \\
\text { pesca }\end{array}$ & $\begin{array}{c}\text { B } \\
\text { Explot } \\
\text { ación } \\
\text { de } \\
\text { minas } \\
\text { y } \\
\text { canter } \\
\text { as }\end{array}$ & $\begin{array}{c}\text { C } \\
\text { Industri } \\
\text { as } \\
\text { manufac } \\
\text { tureras }\end{array}$ & $\begin{array}{c}\text { D } \\
\text { Sumini } \\
\text { stro de } \\
\text { electrici } \\
\text { dad, } \\
\text { gas, } \\
\text { vapor y } \\
\text { aire } \\
\text { acondic } \\
\text { ionado }\end{array}$ & $\begin{array}{c}E \\
\text { Distrib } \\
\text { ución } \\
\text { de } \\
\text { agua; } \\
\text { alcanta } \\
\text { rillado, } \\
\text { gestión } \\
\text { de } \\
\text { desecho } \\
\text { s y } \\
\text { activida } \\
\text { des de } \\
\text { saneam } \\
\text { iento }\end{array}$ & $\begin{array}{l}F \\
\text { Constr } \\
\text { ucción }\end{array}$ & $\begin{array}{c}\text { G } \\
\text { Comer } \\
\text { cio al } \\
\text { por } \\
\text { mayor } \\
\text { y al } \\
\text { por } \\
\text { menor } \\
; \\
\text { repara } \\
\text { ción } \\
\text { de } \\
\text { vehícu } \\
\text { los } \\
\text { autom } \\
\text { otores } \\
\text { y } \\
\text { motoci } \\
\text { cletas }\end{array}$ & $\begin{array}{c}\mathbf{H} \\
\text { Transpo } \\
\text { rte y } \\
\text { almacen } \\
\text { amiento }\end{array}$ & $\begin{array}{c}\text { I } \\
\text { Activi } \\
\text { dades } \\
\text { de } \\
\text { aloja } \\
\text { mient } \\
\text { o y de } \\
\text { servici } \\
\text { o de } \\
\text { comid } \\
\text { as }\end{array}$ & $\begin{array}{l}\mathrm{J} \\
\text { Inform } \\
\text { ación y } \\
\text { comuni } \\
\text { cación }\end{array}$ & $\begin{array}{c}K \\
\text { Activi } \\
\text { dades } \\
\text { financ } \\
\text { ieras } \\
\text { y de } \\
\text { segur } \\
\text { os }\end{array}$ & $\begin{array}{c}\text { M } \\
\text { Activid } \\
\text { ades } \\
\text { profesi } \\
\text { onales, } \\
\text { científi } \\
\text { cas y } \\
\text { técnica } \\
\text { s }\end{array}$ & $\begin{array}{c}\mathrm{N} \\
\text { Activida } \\
\text { des de } \\
\text { servicios } \\
\text { adminis } \\
\text { trativos } \\
\text { y de } \\
\text { apoyo }\end{array}$ & $\begin{array}{c} \\
\text { Adminis } \\
\text { tración } \\
\text { pública } \\
\text { y } \\
\text { defensa; } \\
\text { planes } \\
\text { de } \\
\text { segurida } \\
\text { d social } \\
\text { de } \\
\text { afiliació } \\
\text { n } \\
\text { obligato } \\
\text { ria }\end{array}$ & $\begin{array}{c}P \\
\text { Ense } \\
\text { ñanza }\end{array}$ & $\begin{array}{c}\text { Q } \\
\text { Activi } \\
\text { dades } \\
\text { de } \\
\text { atenci } \\
\text { ón de } \\
\text { la } \\
\text { salud } \\
\text { huma } \\
\text { na y } \\
\text { de } \\
\text { asiste } \\
\text { ncia } \\
\text { social }\end{array}$ & $\begin{array}{c}\text { T } \\
\text { Activi } \\
\text { dades } \\
\text { de los } \\
\text { hogare } \\
\text { s como } \\
\text { emple } \\
\text { adores } \\
\text { como } \\
\text { produ } \\
\text { ctores } \\
\text { de } \\
\text { bienes } \\
\text { y } \\
\text { servici } \\
\text { os } \\
\text { para } \\
\text { uso } \\
\text { propio }\end{array}$ & $\begin{array}{c}\text { Otro } \\
\text { s } \\
\text { servi } \\
\text { cios* }\end{array}$ \\
\hline $7,5 \%$ & $0,4 \%$ & $13,0 \%$ & $0,4 \%$ & $0,4 \%$ & $7,5 \%$ & $27,2 \%$ & $6,2 \%$ & $6,4 \%$ & $1,8 \%$ & $1,3 \%$ & $2,3 \%$ & $2,4 \%$ & $4,2 \%$ & $6,5 \%$ & $3,1 \%$ & $4,2 \%$ & $5,1 \%$ \\
\hline $70,4 \%$ & $0,7 \%$ & $6,5 \%$ & $0,1 \%$ & $0,1 \%$ & $4,7 \%$ & $6,2 \%$ & $2,0 \%$ & $1,7 \%$ &, $3 \%$ &, $1 \%$ &, $2 \%$ &, $5 \%$ & $1,1 \%$ & $1,7 \%$ &, $7 \%$ & $1,5 \%$ & $1,4 \%$ \\
\hline $29,6 \%$ & $0,5 \%$ & $10,7 \%$ & $0,3 \%$ & $0,3 \%$ & $6,5 \%$ & $19,8 \%$ & $4,7 \%$ & $4,7 \%$ & $1,3 \%$ &, $9 \%$ & $1,6 \%$ & $1,7 \%$ & $3,1 \%$ & $4,8 \%$ & $2,3 \%$ & $3,3 \%$ & $3,8 \%$ \\
\hline $7,8 \%$ & $0,5 \%$ & $13,5 \%$ & $0,4 \%$ & $0,3 \%$ & $7,3 \%$ & $26,1 \%$ & $6,0 \%$ & $6,3 \%$ & $1,8 \%$ & $1,3 \%$ & $2,3 \%$ & $2,5 \%$ & $4,7 \%$ & $6,6 \%$ & $3,3 \%$ & $4,2 \%$ & $5,4 \%$ \\
\hline $69,5 \%$ & $0,5 \%$ & $6,7 \%$ & $0,1 \%$ & $0,1 \%$ & $5,2 \%$ & $6,0 \%$ & $1,9 \%$ & $1,7 \%$ &, $3 \%$ &, $1 \%$ &, $2 \%$ & ,6\% & $1,2 \%$ & $1,9 \%$ &, $7 \%$ & $1,9 \%$ & $1,4 \%$ \\
\hline $28,7 \%$ & $0,5 \%$ & $11,2 \%$ & $0,3 \%$ & $0,2 \%$ & $6,6 \%$ & $19,3 \%$ & $4,6 \%$ & $4,7 \%$ & $1,3 \%$ &, $9 \%$ & $1,5 \%$ & $1,9 \%$ & $3,5 \%$ & $5,0 \%$ & $2,4 \%$ & $3,4 \%$ & $4,0 \%$ \\
\hline $10,0 \%$ & $0,5 \%$ & $12,5 \%$ & $0,6 \%$ & $0,4 \%$ & $7,3 \%$ & $25,8 \%$ & $6,3 \%$ & $5,6 \%$ & $1,7 \%$ & $1,0 \%$ & $1,9 \%$ & $1,9 \%$ & $4,6 \%$ & $8,2 \%$ & $3,1 \%$ & $3,4 \%$ & $5,1 \%$ \\
\hline $69,4 \%$ & $0,7 \%$ & $6,3 \%$ & $0,1 \%$ & $0,1 \%$ & $4,5 \%$ & $7,3 \%$ & $1,9 \%$ & $1,7 \%$ & $0,2 \%$ & $0,1 \%$ & $0,2 \%$ & $0,4 \%$ & $1,2 \%$ & $2,0 \%$ & $0,6 \%$ & $2,1 \%$ & $1,2 \%$ \\
\hline $37,5 \%$ & $0,6 \%$ & $9,6 \%$ & $0,3 \%$ & $0,3 \%$ & $6,0 \%$ & $17,2 \%$ & $4,3 \%$ & $3,8 \%$ & $1,0 \%$ & $0,6 \%$ & $1,1 \%$ & $1,2 \%$ & $3,1 \%$ & $5,3 \%$ & $1,9 \%$ & $2,8 \%$ & $3,3 \%$ \\
\hline $9,9 \%$ & $0,6 \%$ & $12,9 \%$ & $0,5 \%$ & $0,4 \%$ & $6,7 \%$ & $25,1 \%$ & $6,4 \%$ & $5,8 \%$ & $1,5 \%$ & $1,0 \%$ & $1,9 \%$ & $2,1 \%$ & $5,1 \%$ & $8,9 \%$ & $3,2 \%$ & $2,9 \%$ & $5,2 \%$ \\
\hline $68,4 \%$ & $0,9 \%$ & $6,4 \%$ & $0,1 \%$ & $0,1 \%$ & $4,8 \%$ & $7,1 \%$ & $2,3 \%$ & $1,7 \%$ & $0,1 \%$ & $0,1 \%$ & $0,1 \%$ & $0,5 \%$ & $1,4 \%$ & $2,1 \%$ & $0,8 \%$ & $1,8 \%$ & $1,4 \%$ \\
\hline $37,0 \%$ & $0,7 \%$ & $9,9 \%$ & $0,3 \%$ & $0,2 \%$ & $5,8 \%$ & $16,7 \%$ & $4,5 \%$ & $3,9 \%$ & $0,9 \%$ & $0,6 \%$ & $1,0 \%$ & $1,4 \%$ & $3,4 \%$ & $5,7 \%$ & $2,1 \%$ & $2,4 \%$ & $3,4 \%$ \\
\hline $9,4 \%$ & $0,4 \%$ & $12,3 \%$ & $0,4 \%$ & $0,4 \%$ & $6,7 \%$ & $26,0 \%$ & $6,9 \%$ & $6,0 \%$ & $1,3 \%$ & $1,3 \%$ & $2,3 \%$ & $2,5 \%$ & $5,1 \%$ & $8,2 \%$ & $3,7 \%$ & $2,6 \%$ & $4,5 \%$ \\
\hline $68,1 \%$ & $0,8 \%$ & $5,8 \%$ & $0,1 \%$ & $0,2 \%$ & $4,7 \%$ & $7,7 \%$ & $2,2 \%$ & $1,8 \%$ & $0,3 \%$ & $0,2 \%$ & $0,2 \%$ & $0,7 \%$ & $1,3 \%$ & $2,1 \%$ & $0,8 \%$ & $1,6 \%$ & $1,2 \%$ \\
\hline $34,6 \%$ & $0,6 \%$ & $9,5 \%$ & $0,3 \%$ & $0,3 \%$ & $5,8 \%$ & $18,1 \%$ & $4,9 \%$ & $4,2 \%$ & $0,9 \%$ & $0,8 \%$ & $1,4 \%$ & $1,7 \%$ & $3,5 \%$ & $5,6 \%$ & $2,4 \%$ & $2,2 \%$ & $3,1 \%$ \\
\hline $9,4 \%$ & $0,4 \%$ & $12,1 \%$ & $0,3 \%$ & $0,4 \%$ & $6,9 \%$ & $25,4 \%$ & $7,0 \%$ & $6,4 \%$ & $1,5 \%$ & $1,2 \%$ & $2,3 \%$ & $2,3 \%$ & $5,5 \%$ & $8,1 \%$ & $3,4 \%$ & $2,6 \%$ & $4,5 \%$ \\
\hline $68,1 \%$ & $0,9 \%$ & $5,8 \%$ & $0,1 \%$ & $0,2 \%$ & $5,0 \%$ & $7,1 \%$ & $2,4 \%$ & $2,0 \%$ & $0,2 \%$ & $0,1 \%$ & $0,2 \%$ & $0,9 \%$ & $1,4 \%$ & $2,1 \%$ & $0,8 \%$ & $1,6 \%$ & $1,1 \%$ \\
\hline $35,2 \%$ & $0,6 \%$ & $9,3 \%$ & $0,2 \%$ & $0,3 \%$ & $6,1 \%$ & $17,4 \%$ & $5,0 \%$ & $4,5 \%$ & $1,0 \%$ & $0,7 \%$ & $1,4 \%$ & $1,7 \%$ & $3,7 \%$ & $5,5 \%$ & $2,3 \%$ & $2,2 \%$ & $3,0 \%$ \\
\hline
\end{tabular}




\begin{tabular}{|c|c|c|c|c|c|c|c|c|c|c|c|c|c|c|c|c|c|c|c|}
\hline \multirow[t]{3}{*}{2013} & $\begin{array}{l}\text { Urb } \\
\text { ano }\end{array}$ & $7,1 \%$ & $0,7 \%$ & $13,3 \%$ & $0,4 \%$ & $0,6 \%$ & $8,1 \%$ & $23,4 \%$ & $6,8 \%$ & $6,8 \%$ & $1,6 \%$ & $1,5 \%$ & $2,5 \%$ & $3,8 \%$ & $4,9 \%$ & $6,6 \%$ & $3,2 \%$ & $3,6 \%$ & $5,1 \%$ \\
\hline & $\begin{array}{c}\text { Rur } \\
\text { al }\end{array}$ & $62,0 \%$ & $0,6 \%$ & $7,5 \%$ & $0,2 \%$ & $0,2 \%$ & $6,4 \%$ & $7,9 \%$ & $2,7 \%$ & $2,4 \%$ & $0,5 \%$ & $0,2 \%$ & $0,3 \%$ & $1,0 \%$ & $2,0 \%$ & $2,2 \%$ & $0,7 \%$ & $2,0 \%$ & $1,4 \%$ \\
\hline & $\begin{array}{c}\text { Tot } \\
\text { al }\end{array}$ & $25,3 \%$ & $0,7 \%$ & $11,3 \%$ & $0,3 \%$ & $0,5 \%$ & $7,6 \%$ & $18,2 \%$ & $5,4 \%$ & $5,3 \%$ & $1,2 \%$ & $1,1 \%$ & $1,8 \%$ & $2,9 \%$ & $3,9 \%$ & $5,1 \%$ & $2,4 \%$ & $3,1 \%$ & $3,9 \%$ \\
\hline \multirow[t]{3}{*}{$\begin{array}{c}\text { PROM } \\
\text { EDIO }\end{array}$} & $\begin{array}{l}\text { Urb } \\
\text { ano }\end{array}$ & $8,7 \%$ & $0,5 \%$ & $12,8 \%$ & $0,4 \%$ & $0,4 \%$ & $7,2 \%$ & $25,6 \%$ & $6,5 \%$ & $6,2 \%$ & $1,6 \%$ & $1,2 \%$ & $2,2 \%$ & $2,5 \%$ & $4,9 \%$ & $7,6 \%$ & $3,3 \%$ & $3,4 \%$ & $5,0 \%$ \\
\hline & $\begin{array}{c}\text { Rur } \\
\text { al }\end{array}$ & $68,0 \%$ & $0,7 \%$ & $6,4 \%$ & $0,1 \%$ & $0,1 \%$ & $5,1 \%$ & $7,0 \%$ & $2,2 \%$ & $1,9 \%$ & $0,3 \%$ & $0,1 \%$ & $0,2 \%$ & $0,7 \%$ & $1,4 \%$ & $2,0 \%$ & $0,7 \%$ & $1,8 \%$ & $1,3 \%$ \\
\hline & $\begin{array}{c}\text { Tot } \\
\text { al }\end{array}$ & $32,6 \%$ & $0,6 \%$ & $10,2 \%$ & $0,3 \%$ & $0,3 \%$ & $6,3 \%$ & $18,1 \%$ & $4,8 \%$ & $4,4 \%$ & $1,1 \%$ & $0,8 \%$ & $1,4 \%$ & $1,8 \%$ & $3,5 \%$ & $5,3 \%$ & $2,3 \%$ & $2,8 \%$ & $3,5 \%$ \\
\hline
\end{tabular}

(*) Debe tomarse en cuenta que los valores resaltados son estimaciones poco precisas basadas en intervalos de confianza. Fuente: Encuesta Nacional de empleo, desempleo y subempleo ENEMDU DIC - 20072013.

Tabla N 7. Caracterización de la agricultura por tamaño y sexo. Ecuador

\begin{tabular}{|c|c|c|c|c|c|c|c|c|c|c|c|c|c|c|c|c|c|c|c|c|}
\hline \multirow{4}{*}{ TAMAÑO } & \multicolumn{15}{|c|}{ AGRICULTURA } & & & & & \\
\hline & \multicolumn{5}{|c|}{ PEQUEÑA } & \multicolumn{5}{|c|}{ MEDIANA } & \multicolumn{5}{|c|}{ EMPRESARIAL } & \multicolumn{5}{|c|}{ TOTAL } \\
\hline & \multicolumn{2}{|c|}{ HOMBRE } & \multicolumn{2}{|c|}{ MUJER } & \multirow{2}{*}{$\begin{array}{c}\text { TOT } \\
\text { AL } \\
\text { UPA }\end{array}$} & \multicolumn{2}{|c|}{ HOMBRE } & \multicolumn{2}{|c|}{ MUJER } & \multirow{2}{*}{$\begin{array}{c}\text { TOT } \\
\text { AL } \\
\text { UPA }\end{array}$} & \multicolumn{2}{|c|}{ HOMBRE } & \multicolumn{2}{|c|}{ MUJER } & \multirow{2}{*}{$\begin{array}{c}\text { TOT } \\
\text { AL } \\
\text { UPA }\end{array}$} & \multicolumn{2}{|c|}{ HOMBRE } & \multicolumn{2}{|c|}{ MUJER } & \multirow{2}{*}{$\begin{array}{c}\text { TOT } \\
\text { AL } \\
\text { UPA }\end{array}$} \\
\hline & UPA & $\%$ & UPA & $\%$ & & UPA & $\%$ & UPA & $\%$ & & UPA & $\%$ & $\begin{array}{c}\text { UP } \\
\mathbf{A}\end{array}$ & $\%$ & & UPA & $\%$ & UPA & $\%$ & \\
\hline menos 1 ha & $\begin{array}{c}76.68 \\
5\end{array}$ & $\begin{array}{c}24, \\
1\end{array}$ & $\begin{array}{c}40.43 \\
5\end{array}$ & $\begin{array}{c}37, \\
8\end{array}$ & $\begin{array}{c}117.1 \\
19\end{array}$ & $\begin{array}{c}33.91 \\
1\end{array}$ & $\begin{array}{c}14, \\
2\end{array}$ & $\begin{array}{c}21.1 \\
74\end{array}$ & $\begin{array}{c}30, \\
1\end{array}$ & $\begin{array}{c}55.08 \\
5\end{array}$ & 70 & 0,2 & 9 & 0,2 & 80 & $\begin{array}{c}110.6 \\
66\end{array}$ & $\begin{array}{c}18 \\
8\end{array}$ & $\begin{array}{c}61.61 \\
8\end{array}$ & $\begin{array}{c}33 \\
8\end{array}$ & $\begin{array}{c}172.2 \\
85\end{array}$ \\
\hline 1 a 2 ha & $\begin{array}{c}51.89 \\
8\end{array}$ & $\begin{array}{c}16, \\
3\end{array}$ & $\begin{array}{c}18.41 \\
4\end{array}$ & $\begin{array}{c}17, \\
2\end{array}$ & $\begin{array}{c}70.31 \\
1\end{array}$ & $\begin{array}{c}24.15 \\
9\end{array}$ & 10 & $\begin{array}{c}9.34 \\
3\end{array}$ & $\begin{array}{c}13, \\
3\end{array}$ & $\begin{array}{c}33.50 \\
2\end{array}$ & 91 & 0,3 & 134 & 2,6 & 225 & $\begin{array}{c}76.14 \\
8\end{array}$ & $\begin{array}{c}12 \\
9\end{array}$ & $\begin{array}{c}27.89 \\
1\end{array}$ & $\begin{array}{c}15, \\
3\end{array}$ & $\begin{array}{c}104.0 \\
39\end{array}$ \\
\hline 2 a 3 ha & $\begin{array}{c}39.72 \\
7\end{array}$ & $\begin{array}{c}12 \\
5\end{array}$ & $\begin{array}{c}11.48 \\
8\end{array}$ & $\begin{array}{c}10 \\
8\end{array}$ & $\begin{array}{c}51.21 \\
5\end{array}$ & $\begin{array}{c}18.18 \\
7\end{array}$ & 7,6 & $\begin{array}{c}6.33 \\
7\end{array}$ & 9,0 & $\begin{array}{c}24.52 \\
4\end{array}$ & 96 & 0,3 & 56 & 1,1 & 152 & $\begin{array}{c}58.01 \\
0\end{array}$ & 9,8 & $\begin{array}{c}17.88 \\
1\end{array}$ & 9,8 & $\begin{array}{c}75.89 \\
1\end{array}$ \\
\hline 3 a 5 ha & $\begin{array}{c}41.39 \\
3\end{array}$ & $\begin{array}{c}13, \\
0\end{array}$ & $\begin{array}{c}13.33 \\
0\end{array}$ & $\begin{array}{c}12 \\
5\end{array}$ & $\begin{array}{c}54.72 \\
4\end{array}$ & $\begin{array}{c}29.69 \\
8\end{array}$ & $\begin{array}{c}12 \\
4\end{array}$ & $\begin{array}{c}9.04 \\
1\end{array}$ & $\begin{array}{c}12, \\
9\end{array}$ & $\begin{array}{c}38.73 \\
9\end{array}$ & 154 & 0,5 & 0 & 0,0 & 154 & $\begin{array}{c}71.24 \\
5\end{array}$ & $\begin{array}{c}12 \\
1\end{array}$ & $\begin{array}{c}22.37 \\
2\end{array}$ & $\begin{array}{c}12, \\
3\end{array}$ & $\begin{array}{c}93.61 \\
7\end{array}$ \\
\hline 5 a 10 ha & $\begin{array}{c}39.74 \\
9\end{array}$ & $\begin{array}{c}12 \\
5\end{array}$ & 9.132 & 8,5 & $\begin{array}{c}48.88 \\
0\end{array}$ & $\begin{array}{c}43.59 \\
1\end{array}$ & $\begin{array}{c}18, \\
2\end{array}$ & $\begin{array}{c}10.8 \\
12\end{array}$ & $\begin{array}{c}15, \\
4\end{array}$ & $\begin{array}{c}54.40 \\
3\end{array}$ & $\begin{array}{c}2.35 \\
8\end{array}$ & 7,4 & 236 & 4,5 & 2.593 & $\begin{array}{c}85.69 \\
7\end{array}$ & $\begin{array}{c}14, \\
5\end{array}$ & $\begin{array}{c}20.17 \\
9\end{array}$ & $\begin{array}{c}11, \\
1\end{array}$ & $\begin{array}{c}105.8 \\
76\end{array}$ \\
\hline 10 a 20 ha & $\begin{array}{c}27.64 \\
3\end{array}$ & 8,7 & 7.541 & 7,1 & $\begin{array}{c}35.18 \\
4\end{array}$ & $\begin{array}{c}33.88 \\
1\end{array}$ & $\begin{array}{c}14, \\
2\end{array}$ & $\begin{array}{c}6.12 \\
3\end{array}$ & 8,7 & $\begin{array}{c}40.00 \\
3\end{array}$ & $\begin{array}{c}8.08 \\
4\end{array}$ & $\begin{array}{c}25 \\
4\end{array}$ & $\begin{array}{l}1.8 \\
44\end{array}$ & $\begin{array}{c}35 \\
3\end{array}$ & 9.927 & $\begin{array}{c}69.60 \\
7\end{array}$ & $\begin{array}{c}11 \\
8\end{array}$ & $\begin{array}{c}15.50 \\
7\end{array}$ & 8,5 & $\begin{array}{c}85.11 \\
5\end{array}$ \\
\hline 20 a 50 ha & $\begin{array}{c}28.64 \\
8\end{array}$ & 9,0 & 4.875 & 4,6 & $\begin{array}{c}33.52 \\
3\end{array}$ & $\begin{array}{c}35.04 \\
8\end{array}$ & $\begin{array}{c}14 \\
7\end{array}$ & $\begin{array}{c}5.09 \\
7\end{array}$ & 7,2 & $\begin{array}{c}40.14 \\
5\end{array}$ & $\begin{array}{c}11.1 \\
09\end{array}$ & $\begin{array}{c}34, \\
9\end{array}$ & $\begin{array}{l}1.8 \\
06\end{array}$ & $\begin{array}{c}34 \\
6\end{array}$ & $\begin{array}{c}12.91 \\
5\end{array}$ & $\begin{array}{c}74.80 \\
5\end{array}$ & $\begin{array}{c}12 \\
7\end{array}$ & $\begin{array}{c}11.77 \\
8\end{array}$ & 6,5 & $\begin{array}{c}86.58 \\
3\end{array}$ \\
\hline 50 a 100 ha & $\begin{array}{c}10.48 \\
1\end{array}$ & 3,3 & 1.243 & 1,2 & $\begin{array}{c}11.72 \\
3\end{array}$ & $\begin{array}{c}14.36 \\
7\end{array}$ & 6,0 & $\begin{array}{c}1.78 \\
0\end{array}$ & 2,5 & $\begin{array}{c}16.14 \\
6\end{array}$ & $\begin{array}{c}5.82 \\
0\end{array}$ & $\begin{array}{c}18, \\
3\end{array}$ & 790 & $\begin{array}{c}15 \\
1\end{array}$ & 6.611 & $\begin{array}{c}30.66 \\
8\end{array}$ & 5,2 & 3.812 & 2,1 & $\begin{array}{c}34.48 \\
0\end{array}$ \\
\hline $\begin{array}{c}100 \text { a } 200 \\
\text { ha }\end{array}$ & 2.076 & 0,7 & 324 & 0,3 & 2.399 & 4.291 & 1,8 & 419 & 0,6 & 4.710 & $\begin{array}{c}2.15 \\
6\end{array}$ & 6,8 & 211 & 4,0 & 2.367 & 8.522 & 1,4 & 954 & 0,5 & 9.476 \\
\hline $\begin{array}{c}200 \text { a mas } \\
\text { ha }\end{array}$ & 445 & 0,1 & 71 & 0,1 & 516 & 2.017 & 0,8 & 197 & 0,3 & 2.214 & $\begin{array}{c}1.91 \\
4\end{array}$ & 6,0 & 132 & 2,5 & 2.045 & 4.376 & 0,7 & 400 & 0,2 & 4.775 \\
\hline TOTAL & $\begin{array}{c}318.7 \\
43\end{array}$ & $\begin{array}{c}100 \\
, 0\end{array}$ & $\begin{array}{c}106.8 \\
52\end{array}$ & $\begin{array}{c}100 \\
, 0\end{array}$ & $\begin{array}{c}425.5 \\
96\end{array}$ & $\begin{array}{c}239.1 \\
49\end{array}$ & $\begin{array}{c}100 \\
, 0\end{array}$ & $\begin{array}{c}70.3 \\
23\end{array}$ & $\begin{array}{c}100 \\
, 0\end{array}$ & $\begin{array}{c}309.4 \\
71\end{array}$ & $\begin{array}{c}31.8 \\
51\end{array}$ & $\begin{array}{c}100 \\
, 0\end{array}$ & $\begin{array}{l}5.2 \\
18\end{array}$ & $\begin{array}{c}100 \\
, 0\end{array}$ & $\begin{array}{c}37.06 \\
9\end{array}$ & $\begin{array}{c}589.7 \\
43\end{array}$ & $\begin{array}{c}100 \\
, 0\end{array}$ & $\begin{array}{c}182.3 \\
93\end{array}$ & $\begin{array}{c}100 \\
, 0\end{array}$ & $\begin{array}{c}772.1 \\
36\end{array}$ \\
\hline
\end{tabular}

Fuente: Encuesta de Superficie y Producción Agropecuaria (ESPAC) - 2013 
El estado ecuatoriano debe asumir la responsabilidad de retribuir al desarrollo social, económico y productivo del sector agropecuario mediante el uso del gasto público. En palabras de Barcelata Chávez Hidalgo "el gasto público debe seguir siendo considerado como factor de impulso al desarrollo y que para asegurar el funcionamiento adecuado de la economía y garantizar el bienestar social, es necesario incrementarlo, tal como lo hacen los países más desarrollados... (2007)". La FAO acota que "el gasto público representa un esfuerzo del país para atender necesidades nacionales prioritarias y financiar programas fundamentales de la política de desarrollo. Actualmente existe consenso sobre el papel del Estado en varias funciones indispensables para el desarrollo económico y social dentro del sistema vigente de economía social de mercado (2007)".

Ecuador según precisiones de Yannuzzelli "el gasto público agropecuario ha mantenido una asignación promedio del $2 \%$ del total del gasto público nacional,... el gasto público ha evolucionado de una manera rápida, gracias a los volúmenes de venta de los barriles de petróleo, pero la asignación de recursos sigue siendo precaria y preocupante, ya que las variaciones del gasto público agropecuario son mínimas sin si quiera asemejarse a la asignación adecuada de recursos" (2017). Para evaluar y determinar el interés que presenta el estado en atender las necesidades de la población que se dedica a la agricultura en función de lo que brinda este sector. Es necesario determinar la participación porcentual del PIB Agrícola sobre el PIB total en dividendo de la participación porcentual del gasto público agrícola sobre el gasto público total.

En esta metodología de evaluación Yannuzzelli (2017), manifiesta también que "la asignación de recursos monetarios del gasto público al sector agropecuario no se asemeja, ni se iguala al aporte generado por mencionado sector al producto interno bruto, dicha aseveración se respalda con la obtención del Índice de Orientación Agrícola, la cual presenta un promedio de 0.19 en el período estudiado del 2005 - 2015, sin si quiera llegar a la media de la unidad" (Tabla $\mathrm{N}^{\circ} 8$ ).

Tabla N 8. Índice de Orientación Agrícola. Ecuador

\begin{tabular}{cccccccc}
\hline EJERCICIO & $\begin{array}{c}\text { Gasto } \\
\text { Publico } \\
\mathbf{2 0 0 5 - 2 0 1 5}\end{array}$ & $\begin{array}{c}\text { Gasto Publico } \\
\text { Sector } \\
\text { Agropecuario }\end{array}$ & $\begin{array}{c}\text { Producto } \\
\text { Interno Bruto } \\
\mathbf{2 0 0 5 - 2 0 1 5}\end{array}$ & $\begin{array}{c}\text { PIB } \\
\text { (Agricultura; } \\
\text { acuicultura y } \\
\text { pesca de } \\
\text { camarón; } \\
\text { pesca excepto } \\
\text { camarón) 2005 }\end{array}$ & $\begin{array}{c}\text { Aporte del } \\
\text { Gasto } \\
\text { Publico al } \\
\text { sector } \\
\text { agropecuario }\end{array}$ & $\begin{array}{c}\text { Participación } \\
\text { del sector } \\
\text { agropecuario } \\
\text { en el PIB }\end{array}$ & $\begin{array}{c}\text { Índice de } \\
\text { Orientación } \\
\text { Agrícola }\end{array}$ \\
& & & & & & & \\
& & & & -2015 & & & \\
\hline $\mathbf{2 0 0 5}$ & $\$ 7.914,71$ & $\$ 164,71$ & $\$ 47.809 .319,00$ & $\$ 4.423 .717,00$ & $2,08 \%$ & $9,25 \%$ & $\mathbf{0 , 2 2}$ \\
$\mathbf{2 0 0 6}$ & $\$ 9.617,65$ & $\$ 119,48$ & $\$ 49.914 .615,00$ & $\$ 4.614 .324,00$ & $1,24 \%$ & $9,24 \%$ & $\mathbf{0 , 1 3}$ \\
$\mathbf{2 0 0 7}$ & $\$ 10.015,07$ & $\$ 123,62$ & $\$ 51.007 .777,00$ & $\$ 4.772 .112,00$ & $1,23 \%$ & $9,36 \%$ & $\mathbf{0 , 1 3}$ \\
$\mathbf{2 0 0 8}$ & $\$ 13.838,90$ & $\$ 245,50$ & $\$ 54.250 .408,00$ & $\$ 4.851 .668,00$ & $1,77 \%$ & $8,94 \%$ & $\mathbf{0 , 2 0}$ \\
$\mathbf{2 0 0 9}$ & $\$ 14.200,80$ & $\$ 430,03$ & $\$ 54.557 .732,00$ & $\$ 4.934 .884,00$ & $3,03 \%$ & $9,05 \%$ & $\mathbf{0 , 3 3}$ \\
$\mathbf{2 0 1 0}$ & $\$ 16.124,69$ & $\$ 256,24$ & $\$ 56.481 .055,00$ & $\$ 4.971 .366,00$ & $1,59 \%$ & $8,80 \%$ & $\mathbf{0 , 1 8}$ \\
$\mathbf{2 0 1 1}$ & $\$ 19.791,13$ & $\$ 293,82$ & $\$ 60.925 .064,00$ & $\$ 5.366 .155,00$ & $1,48 \%$ & $8,81 \%$ & $\mathbf{0 , 1 7}$ \\
$\mathbf{2 0 1 2}$ & $\$ 22.253,15$ & $\$ 403,44$ & $\$ 64.362 .433,00$ & $\$ 5.407 .764,00$ & $1,81 \%$ & $8,40 \%$ & $\mathbf{0 , 2 2}$ \\
$\mathbf{2 0 1 3}$ & $\$ 26.889,38$ & $\$ 346,48$ & $\$ 67.546 .128,00$ & $\$ 5.769 .740,00$ & $1,29 \%$ & $8,54 \%$ & $\mathbf{0 , 1 5}$ \\
$\mathbf{2 0 1 4}$ & $\$ 29.813,56$ & $\$ 429,99$ & $\$ 70.243 .048,00$ & $\$ 6.025 .854,00$ & $1,44 \%$ & $8,58 \%$ & $\mathbf{0 , 1 7}$ \\
$\mathbf{2 0 1 5}$ & $\$ 27.373,25$ & $\$ 452,07$ & $\$ 70.353 .852,00$ & $\$ 6.256 .473,00$ & $1,65 \%$ & $8,89 \%$ & $\mathbf{0 , 1 9}$ \\
\hline
\end{tabular}

Fuente: Yannuzzelli. El índice de orientación agrícola (IOA) como mecanismo del análisis del gasto público agropecuario ecuatoriano. Período 2005 - 2015. 


\section{Conclusión}

La Republica del Ecuador es consciente de la importancia y trascendencia no solo histórica, sino económica y social que tiene el sector agropecuario para el país, ante esta realidad se manifiesta tener una deuda histórica con el pequeño agricultor familiar campesino quien representa el mayor porcentaje de la población rural y dedicada principalmente a la agricultura. A pesar de esto y su interés histórico de establecer un marco legal y político para la agricultura no ha priorizado el derecho distributivo y equitativo que demanda este grupo social sobre ciertos recursos vitales para el proceso productivo como tierra, agua, tecnología, crédito y financiamiento público.

Las políticas agrícolas generadas y promulgadas por el Estado ecuatoriano no han generado el impacto esperado sobre el pequeño agricultor campesino, priorizando el desarrollo del grande y mediano productor o relegando al sector agrícola por debajo de otros sectores. Es necesario implementar políticas públicas orientadas a la tenencia de la tierra, gestión del agua, desarrollo tecnológico, financiamiento y desarrollo Agrícola que generen una distribución, gestión y equilibrada asignación de los recursos en beneficio primordial del pequeño agricultor.

\section{Bibliografía}

Abbott, P. (1998). Competition Policy and Agricultural Trade. Organisation de Coopération et de Développement Economiques.

Acosta, A. (2010). La comunicación, un derecho necesario para el Buen Vivir. En Cordero, D. H. (Ed.), Nuevas instituciones del derecho constitucional ecuatoriano, Quito: INREDH

Aguilar A. y Lima F. (2005). Las políticas públicas: su aporte. Democracia, desarrollo y políticas públicas.

Asamblea Constituyente, R. O. (2008). Constitución de la República del Ecuador. Quito.

Barcelata, H. (2007). LAS FINANZAS PÚBLICAS EN MÉXICO. 1988-2006. México: Eumed.

BM, Banco Mundial (1986). Poverty and Hunger: Issues and Options for Food Security in Developing Countries. Washington DC.

BM, Banco Mundial. (1994). La ordenación de los recursos hídricos, Estados Unidos. ISBN: 0-82132638-4

Bucaram, Jacobo. (2017). Réquiem por la Cuenca del Río Guayas. Universidad Agraria del Ecuador. ISBN: 978-9942-8629

CEPAL, Comisión Económica para América Latina y el Caribe. (1954) El desarrollo económico del Ecuador. Publicación de las Naciones Unidas, México.

CEPAL, Comisión Económica para América Latina y el Caribe. (2009) Panorama Social de América Latina 2008. Santiago de Chile: Comisión Económica para América Latina y el Caribe, CEPAL

CEPAL, Comisión Económica para América Latina y el Caribe. (2012) Población, territorio y desarrollo sostenible. Comité especial de la CEPAL sobre Población y Desarrollo, Ecuador.

Duque, E. (2015). Seminario Metodología de la Investigación, Universidad Nacional de Colombia

Echeverri, Rafael y Ribero, María. (2002). Nueva ruralidad: visión del territorio en América Latina y

el Caribe. San José: Instituto Interamericano de Cooperación para la Agricultura - IICA

FAO, Organización de las Naciones Unidas para la Alimentación y la Agricultura (2004). Política de desarrollo agrícola. Roma.

INEC, Instituto Nacional de Estadísticas y Censos. (2017). Encuesta Nacional de Empleo, Desempleo y Subempleo. Indicadores Laborales, Quito

Jaramillo, Byron. (2013). Análisis de la evolución de los Servicios de Extensión y Transferencia Tecnológica (Setta) en la Región Andina. Producto 3: Informe Ecuador. Banco Interamericano de Desarrollo. 
Jollivet, Marcel (2003). "Comment se fait la sociología : à propos d'une controverse en sociologie rurale", en, Sociétés Contemporaines, $\mathrm{N}^{\circ}$ 49-50, pp.43-60

Klein, B.; Meyer, R.; Hannig, A.; Burnett, J.; y Fiebig, M. Better. (1999) Practices in Agricultural Lending, Agricultural Finance. Revisited No. 3, FAO y GTZ, Roma

Lasswell, H. (1963). El futuro de la ciencia politica, Edit. Tecnos

Lewin, Kurt 1946. Action research and minority problems. Journal of Social: 34-46.

MAGAP, Ministerio de Agricultura, Ganaderia, Acuacultura y Pesca. (2016). La política agropecuaria ecuatoriana: hacia el desarrollo territorial rural sostenible: 2015-2025 I Parte, ISBN: 978-9942-22-0196. Quito

MAGAP, Ministerio de Agricultura, Ganaderia, Acuacultura y Pesca. (2016). La política agropecuaria ecuatoriana: hacia el desarrollo territorial rural sostenible: 2015-2025 II Parte, ISBN: 978-9942-22019-6. Quito

Martínez Valle, Luciano. (2006). La perspectiva local-global en el medio rural ecuatoriano. Revista de Ciencias Sociales Iconos. Num. 24. Quito: FLACSO, Facultad Latinoamericana de Ciencias Sociales. Martínez Valle, Luciano. (2009). La pluriactividad entre los pequeños productores rurales: el caso ecuatoriano. En La pluriactividad en el campo latinoamericano (1st ed., pp. 81-101). Quito: FLACSO, Facultad Latinoamericana de Ciencias Sociales.

Martínez, Luciano. (2013). La Agricultura Familiar en el Ecuador. Fondo Internacional de Desarrollo Agrícola - FIDA y el Centro Latinoamericano para el Desarrollo Rural - RIMISP, Quito

Mendras, Henri (1984). La fin des paysans, Babel, Arles.

Munro Faure, P.; Groppo, P.; Herrera, A.; y Palmer, D. (2002). Land tenure and rural development projects, Land Tenure Studies, Roma, págs 2 y 3

Quinde-Rosales, Francisco. (2017). Modelo de Regresión Lineal, para medir la incidencia del sector bancario en el sector agrícola primario ecuatoriano, Período 2005-2015. Guayaquil

Quinde-Rosales, Victor. (2011). Evolución del Gasto Público Agropecuario y Rural en el Ecuador Periodo 2000-2009. Ecuador: Universidad Agraria del Ecuador - UAE

Quinde-Rosales, Victor. (2015). Efecto de la Intervencion Estatal en la Regulación de los Precios del Arroz Canton Daule. Guayaquil

RICYT, Red de Indicadores de Ciencia y Tecnología -Iberoamericana e Interamericana (2017). RICYT. Recuperado el 1 de Junio de 2017, de http://www.ricyt.org/comparativos-sp-469065143

Rodríguez, Jorge (2002). Distribución territorial de la población de América Latina y el Caribe: tendencias, interpretaciones y desafíos para las políticas públicas. Centro Latinoamericano y Caribeño de Demografía - CELADE, División de Población. Santiago: CEPAL, Comisión Económica para América Latina y el Caribe.

Rossel, Cecilia. (2012). Protección social y pobreza rural en América Latina. Informe de Consultoría. Comisión Económica para América Latina y el Caribe, CEPAL. Santiago.

Shanin, Teodor (1976). Naturaleza y lógica de la economía campesina, Editorial Anagrama, Barcelona. Silva Lira, Iván. (2005) Desarrollo Económico Local y Competitividad territorial. Revista CEPAL. Num. 85. Santiago: CEPAL, Comisión Económica para América Latina y el Caribe.

Subsecretaria de Riego y Drenaje. (2011). Plan Nacional de Riego y Drenaje, PNRD. Ministerio de Agricultura, Ganaderia, Acuacultura y Pesca, MAGAP. Ecuador

Tepicht. Jerzy (1973). Marxisme et agriculture: Le paysan polonais, Armand Colin, Paris.

Umali Deininger, D. (1997). Public and Private Agricultural Extension: Partners or Rivals?, The World Bank Research Observer, tomo 12, No. 2, pág. 203

Villacís B., Carrillo D. (2012). País atrevido: la nueva cara sociodemográfica del Ecuador. Edicón especial revista Analitika. Instituto Nacional de Estadística y Censos (INEC). Quito - Ecuador

Yannuzzelli, J. (2017). El índice de orientación agrícola (IOA) como mecanismo del análisis del gasto público agropecuario ecuatoriano. Período 2005 - 2015. Guayaquil 